\title{
The effect of size and replacement content of nanosilica on strength development of cement treated residual soil
}

\begin{abstract}
In this study, effects of size and replacement content of nanosilica on physical, chemical, and microstructural characteristics of cemented residual soil were investigated. Accordingly, UCS and electrical resistivity tests were conducted on cemented specimens with replacement contents of $0.2 \%-1 \%$ nanosilica of 15 and $80 \mathrm{~nm}$ at 7, 14 and 28 days. XRD, Zeta potential, CEC, FTIR, and SEM tests were performed to identify chemical and microstructural changes over time. The results showed that smaller size nanosilica had an accelerated influence on samples while nanosilica of larger size was more effective at ages after 14 days of curing.
\end{abstract}

Keyword: Nanosilica; Cement treated residual soil; Chemical composition; Microstructural properties; Curing time 